\title{
THE CHEMICAL CONTROL OF WEEDS ON SUGAR-CANE ESTATES OF JAVA')
}

\author{
J. RUINARD \\ former Agronomist of the Netherlands Trading Cy on Java
}

\section{SUMMaRY}

On sugar-cane estates in Indonesia a great deal of trouble is caused by weeds, particularly in the period between the preparation of the soil and the plantation getting closed. This weed vegetation chiefly consists of grasses, although Cyperaceae and Dicotyledones are usually present as well. It has been found that chemical control methods can yield good results provided the treatment is adapted to the method of tillage of the soil (the Reynoso system) and the type of weed vegetation in het younger gardens (this vegetation originated directly from the weedcover which existed before the soil was tilled).

Spraying with herbicides immediately after tilling did not give very good results, but by spraying the surface before tilling with a mixture of TCA and the ammonium salt of 2,4-D in doses of 20 and 2 kilos per hectare respectively it is possible to keep the gardens substantially clear of weeds up to eight weeks after treatment. The best results are obtained from this control method by digging the trenches as soon as possible after spraying and then planting the site as quickly as possible.

For large-scale spraying a spraying set has been evolved which consists of a portable power pump, an 8.5-metre boom with twelve nozzles, and a connecting hose about 100 metres long; with this equipment an area of from 2.5 to 3 hectares can be sprayed in an hour.

\section{INTRODUCTION}

Generally speaking, weeds cause a great deal of trouble to sugar-cane cultivation in Java, particularly in the period between the preparation of the soil and the plantation getting closed. Even at present the weeds are still kept within bounds by continuous weeding, but on some estates frequent weeding is out of question owing to the persistent shortage of labour. In other areas there is often a temporary time-lag in the weeding schedule when a disproportionately large number of locally available workers are employed by smallholders near the estates. Moreover weeding costs are continually rising as a result of the increasing cost of living.

For these reasons the present writer was requested by the Netherlands Trading Company to work out a method for the chemical control of weeds at the company's Sumberhardjo sugar estate during the period from 1953 to 1956 ; the method was adapted to the usual way of growing sugar-cane in Java.

\section{METHOD OF PREPARING THE SOIL}

In Java the soil is prepared according to the Reynoso system. Soon after the rice harvest the drainage system is excavated in the still wet soil; this system consists of a network of drains $50 \mathrm{~cm}$ wide and $60 \mathrm{~cm}$ deep, their distance apart being 8 metres, with $70 \mathrm{~cm}$ wide and $80 \mathrm{~cm}$ deep main drains 125 metres apart and at right-angles to the former. The land is thus divided into strips 125 metres in length and 8 metres wide. After the lapse of some weeks trenches are dug at right-angles to the longitudinal direction of the beds.

1) Received for publication October 2, 1959. 
These trenches are 8 metres long, $40 \mathrm{~cm}$ wide and $25 \mathrm{~cm}$ deep. The earth excavated is thrown up into ridges on the $70 \mathrm{~cm}$ wide untouched strips between the trenches. The 15 to $20 \mathrm{~cm}$ thick top layer of soil from the trenches is excavated by means of patjols (heavy hoes). The soil is usually so heavy and moist that the clods do not disintegrate. The workmen turn the clods as well as they can when they deposit them beside the trenches. The second layer of earth 5 to $10 \mathrm{~cm}$ thick is removed from the trenches with forks and placed on the top of the ridges. Some properly constructed trenches and ridges are shown diagrammatically in Fig. 1.

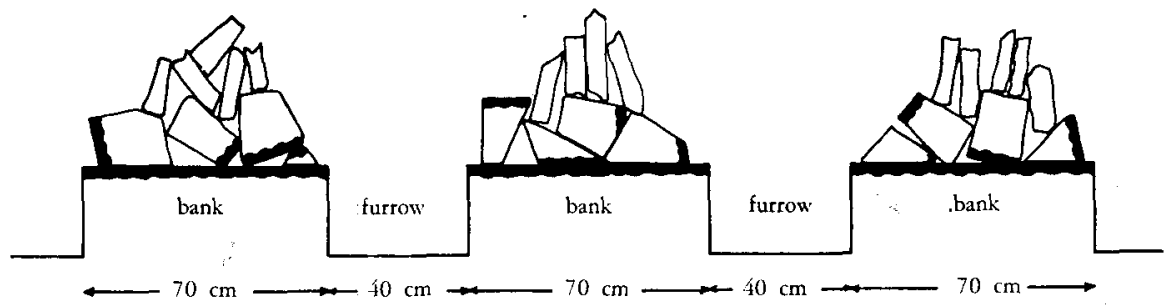

Fig. 1 Choss-section of some furrows and banks immediately after excavating the FURROWS ; THE UPPER SOIL LAYER IS MARKED BY A THICK, UNDULATING LINE.

As soon as the clods on the ridges after some weeks have partly disintegrated, the top layer is returned into the trenches. The cuttings are planted in this bed which is about $10 \mathrm{~cm}$ thick. The first earthing-up operation takes place about three weeks afterwards, the trenches being filled with earth from the ridges to $10 \mathrm{~cm}$ below the surface. After about five weeks have elapsed the plants are earthed-up for the second time, the remainder of the ridges being replaced in the trenches.

\section{ThE TYPE OF WEED vegetation IN THE YOUNG PLANTATION}

At the commencement of tilling operations the land is usually covered with a dense sward of weeds. Some of the surface vegetation is choked owing to the fact that the clods from the trenches are more or less turned before the workmen deposit them on the untouched strips between the trenches. But as Fig. 1 shows, light and air are able to enter freely large sections of the original surface. Consequently even only a few days after the trenches have been dug large numbers of weeds emerge from cracks in the ridges and along the sides of the latter.

The soil thrown into the trenches during the preparation for planting and the first earthing up only contains a small number of viable parts of weeds. It is not until the second earthing-up that most of the original top layer which is rich in seeds, roots and rhizomes is returned into the trenches. Accordingly the weed vegetation in the young sugar-cane plantation is concentrated on the ridges. These weeds tend to overgrow the young plants in the trenches. It is not until the second earthing-up that the weed growth in the actual trenches becomes an important factor. At this stage, however, the plantation is rapidly getting closing, so that the majority of these weeds are destroyed through lack of light. In such gardens weed control is no longer required.

Most of the weeds in young sugar-cane gardens usually are grasses. As a 
rule Cyperaceae represent a good proportion of the vegetation. Dicotyledones are generally also found, but mostly in small numbers only.

It follows from this discussion of the type of weed vegetation that control methods should be directed to the destruction of the weeds on the ridges between the trenches.

\section{Chemical CONTROL AFTER EXCAVATION OF THE tRenChes}

Little was achieved by spraying, immediately prior to planting, with such contact herbicides as oils and pentachlorophenol. A few weeks afterwards the weed growth had entirely recovered.

Better prospects were afforded by the use of the sodium salt and butyl ester of 2,4-D. About a week before planting they were administered in doses varying from 1 to 6 kilos per hectare. In order to destroy such grasses as had aiready emerged the land was weeded before spraying or pentachlorophenol was added to the spray. The results were nevertheless disappointing. The spray mist did not penetrate to a sufficient depth into the fissures on the ridges so that most of the weeds which were taking root there could continue their development undisturbed. Moreover it was found that the 2,4-D in the bed had killed a large number of sugar-cane cuttings and retarded the development of the others.

The addition of TCA to the spray prevented the germination of seeds, roots and rhizomes of grasses in the surface layers, but the other drawbacks of the treatment (viz. weed development from cracks in the ridges and the harmful effect of the herbicides on the plant material and the young cane) were present to the same extent.

CMU administered in doses of 2 to 5 kilos per hectare gave the same results as the mixtures of TCA and 2,4-D.

\section{Chemical control before excavation of the trenches}

It seemed likely that the disadvantages of spraying after the trenches had been dug might be overcome by a treatment of the surface immediately prior to trenching; such a treatment would eliminate the weed vegetation which would otherwise develop on the ridges after trenching and there also would be no question of the herbicides being mixed with the layer of soil which would afterwards form the planting bed.

Spraying the surface vegetation with contact herbicides had some effect, but the killing was confined to the parts of the weed on the surface. Shortly afterwards most of the weeds had entirely recovered.

On the other hand, surface treatment with a mixture of TCA and the ammonium salt of 2,4-D in doses of 20 and 2 kilos per hectare respectively gave very satisfactory results. The latter herbicide kills Dicotyledones and Cyperaceae, while the former boosts the effect of TCA on Cyperaceae and destroys grasses. Garden sections thus treated remained substantially free from weeds up to eight weeks after spraying, i.e. five to six weeks after planting the cane. In most cases a further weeding was desirable before the plantation got closed. When there is sufficient labour available weeding is usually carried out at least five or six times during the period between the preparation of the soil and the crop getting closed. Consequently chemical control saves at least four or five weedings. 
It was investigated whether the surface treatment with TCA and 2,4-D had a harmful effect on the sugar-cane. Plot $\mathrm{A}$ of an experiment was frequently weeded until the crop was two months old. Plot B was treated with 20 kilos of TCA and 2 kilos of ammonium salt of 2,4-D per hectare some days before digging the trenches, after which there were two further weedings shortly before the plantation as getting closed. In plot B the crop tillered better than in plot $\mathrm{A}$ and also produced an extra 5 tons of cane and 650 kilos of sugar per hectare. Hence there was no question of the herbicides having had a harmful effect on the cane. The higher yield of plot B must be clearly regarded as the result of the prolonged suppression of the weeds.

Similar results were obtained with CMU in a dose of 5 kilos per hectare, but at the time in question this herbicide was too expensive for large-scale use.

\section{CONTROL TEChNIQUE}

When knapsack sprays are employed the capacity per workman is too low to make chemical control profitable. On the other hand it was not possible in Java to spray the land from aircraft. Hence a compromise was made.

For the large-scale spraying operations use was made of a 8.5 metre boom to which were connected ten "Lyunet 1,6/3,4" nozzles. These give a conical spray with a vertical angle of $90^{\circ}$. The outside nozzles only have half the liquid capacity of the others; they have a narrower spray cone and are skew to the axis of the boom. All nozzles are so positioned as to ensure a uniform distribution of the herbicides over the strip sprayed (cf. Fig. 2). The boom is

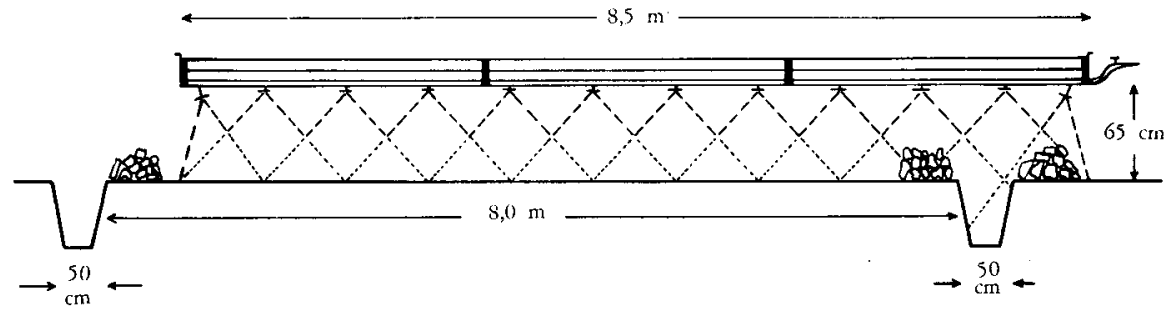

Fig. 2 Diagram of a SPRAYing boom and its position with Respect to Each StRip TO BE SPRAYED.

carried by two workmen, and is connected by a hose about 100 metres in length to a "Bimoto Cadet" power pump placed centrally in the site to be sprayed. The power pump and a liquid container holding 100 litres are on a wooden rack which is easily moved. The working presure of the pump is adjusted to 20 atms. gauge, the capacity of the twelve nozzles totalling about 1,000 litres an hour. The workmen carrying the boom walk at a speed of about $4 \mathrm{~km}$ p.h. An area of 2.5 to 3 hectares an hour can be treated, depending on the shape and type of field to be sprayed.

Fig. 3 shows the method of treating a garden. The thick full lines represent the main drains, the thin full lines the drains, and the broken lines the boundaries of the areas treated from a single location of the power pump. The small numbered rectangles denote the successive locations of the power pump. The arrows indicate the directions in which the boom is moved.

The effect of the spraying operations is influenced by weather conditions. 
The best results are obtained by spraying in sunny, calm weather on a weed vegetation which is not too moist. For this reason the treatment was preferably applied between 7 a.m. and noon.

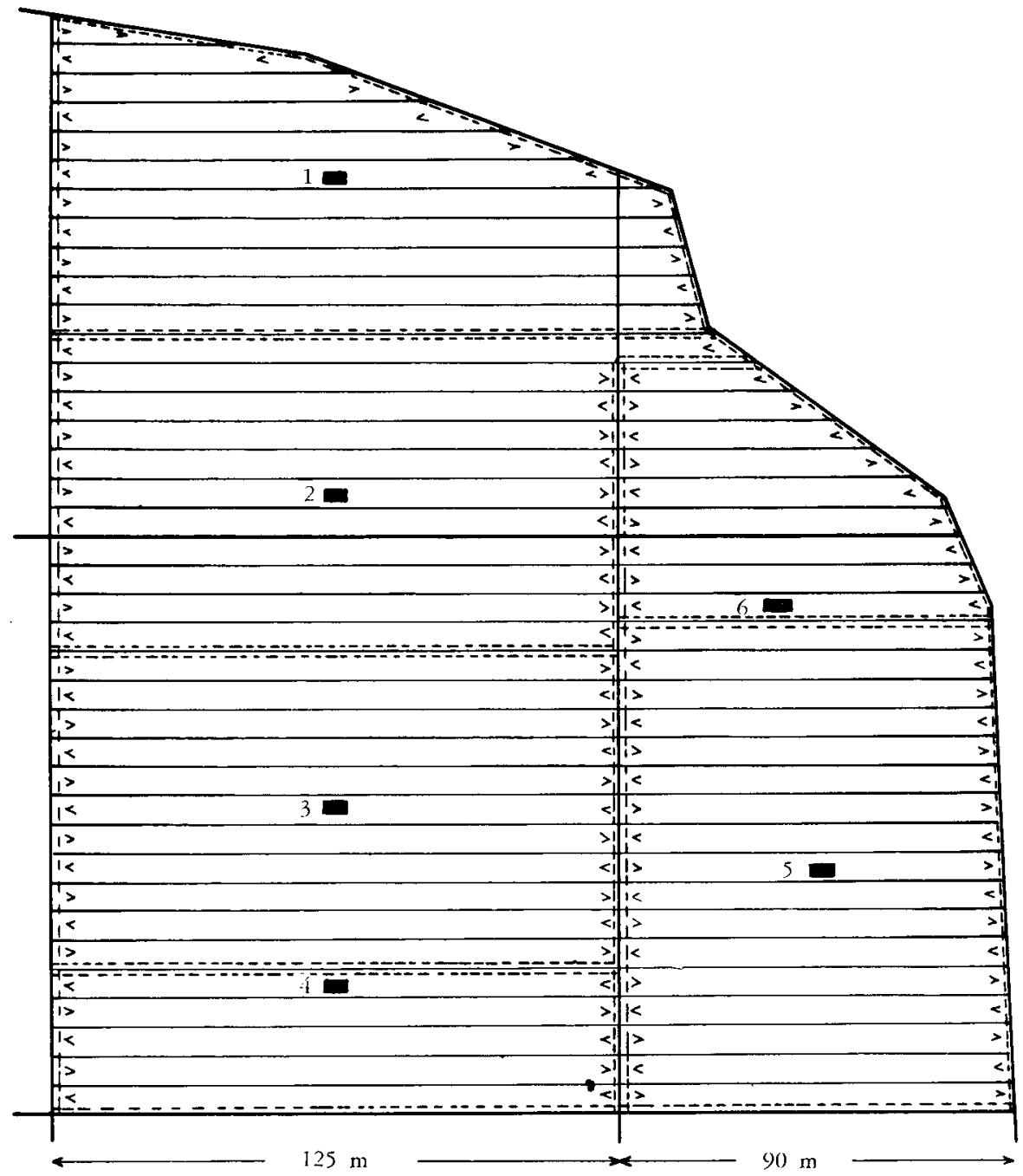

Fig. 3 Example of a practical subdivision of a sugarcane field to be sprayed.

\section{ACKNOWLEDGEMENT}

The author wishes to express his gratitude to the Netherlands Trading Company for their permission to publish the results of the experiments, to Mr. L. VAN VuUneN for his valuable advice during the investigation, and to Mr. J. E. WILson for his kindness in translating the manuscript. 